\title{
TECHNICAL PROPERTIES AND RESEARCH CAPABILITIES OF THE TRUCK SIMULATOR OWNED BY THE MILITARY INSTITUTE OF AVIATION MEDICINE - A NEW PERSPECTIVE IN RESEARCH ON TRUCK DRIVERS
}

\author{
Paulina BARAN ${ }^{1}$, Mariusz KREJ', Marcin PIOTROWSKI'2, Łukasz DZIUDA ${ }^{1}$ \\ 1 Department of Psychophysiological Measurements and Human Factor Research, Military Institute of \\ Aviation Medicine, Warsaw, Poland \\ 2 Department of Simulator Studies and Aeromedical Training, Military Institute of Aviation Medicine, Warsaw, \\ Poland
}

\begin{abstract}
Source of support: The truck simulator described in this paper has been modernized under the project entitled "Multidisciplinary Research Center of Cardinal Stefan Wyszyński University in Warsaw", financed by the European Regional Development Fund under the Regional Operational Program of the Masovian Voivodeship for 2014-2020 (Contract No. RPMA.01.01.00-14-8496/17-00).
\end{abstract}

Author's address: P. Baran, Department of Psychophysiological Measurements and Human Factor Research, Military Institute of Aviation Medicine, Krasińskiego Street 54/56, 01-755 Warsaw, e-mail: pbaran@wiml.waw.pl.

Abstract: This paper is aimed at presenting basic technical properties and possibilities of using the truck simulator owned by the Military Institute of Aviation Medicine (MIAM). The truck driving simulator is a stationary device, equipped with a six degrees of freedom (6 DoF $\mid$ ) motion system and reproducing the functionality of a truck on the basis of the Mercedes Benz Actros cabin. It is intended for conducting research as well as training truck drivers in simulated traffic conditions.

Keywords: car drivers, truck simulators, virtual reality, road traffic safety 


\section{INTRODUCTION}

The market of car driving simulators is constantly growing [12]. Driving simulation devices are used in scientific research more and more often, as they provide a fully safe and controlled environment for testing various driving behaviours efficiently. Such devices are regarded as attractive and innovative research tools in the field of transportation as they allow to create rich virtual reality and repeatable experimental conditions while controlling and reducing the impact of distractors on drivers' behaviours $[2,10]$.

Studies using technologically advanced driving simulators are conducted in a wide range of settings and relate to, for example, the effects of distractors on driving performance [8], the impact of cooling on the psychophysiological state of the driver [11], alcohol and drug-induced effects on driving [6,14], the impact of aging processes on driving ability [3], the risks and consequences of drowsiness and fatigue while driving $[1,5,7,9]$, the impact of using mobile phones on driving safety [13], as well as the effects of eating and drinking on driving performance [16]. It should be noted, however, that the degree of technical advancement of the simulator's software and its mechanical systems determines the level of realism, as well as the possibilities of creating road situations and their diversity. In technologically advanced simulators, it is possible to create such conditions and induce such behaviours in drivers as in real road traffic, which was confirmed in research [15].

Despite numerous advantages and benefits of using car driving simulators, they are not devices without drawbacks, among which high costs of construction and the possibility of inducing symptoms of simulator sickness [4] can be mentioned. Nevertheless, there is still great demand and interest when it comes to using virtual reality in scientific research.

The main purpose of this paper is to present the basic technical properties and possibilities of using the technologically advanced truck simulator, owned by the Military Institute of Aviation Medicine (MIAM) in research on car drivers. The results of tests with the use of the simulator will be the subject of a separate paper.

\section{GENERAL DESIGN}

The truck driving simulator is a stationary device, equipped with a six-degree motion system reproducing the functioning of the real truck. It has been designed to carry out trainings of drivers in simulated traffic conditions, as well as to conduct scientific research focused on different aspects of safe driving. The simulator meets the requirements of the Regulation of the Minister of Infrastructure of October 10, 2019 amending the

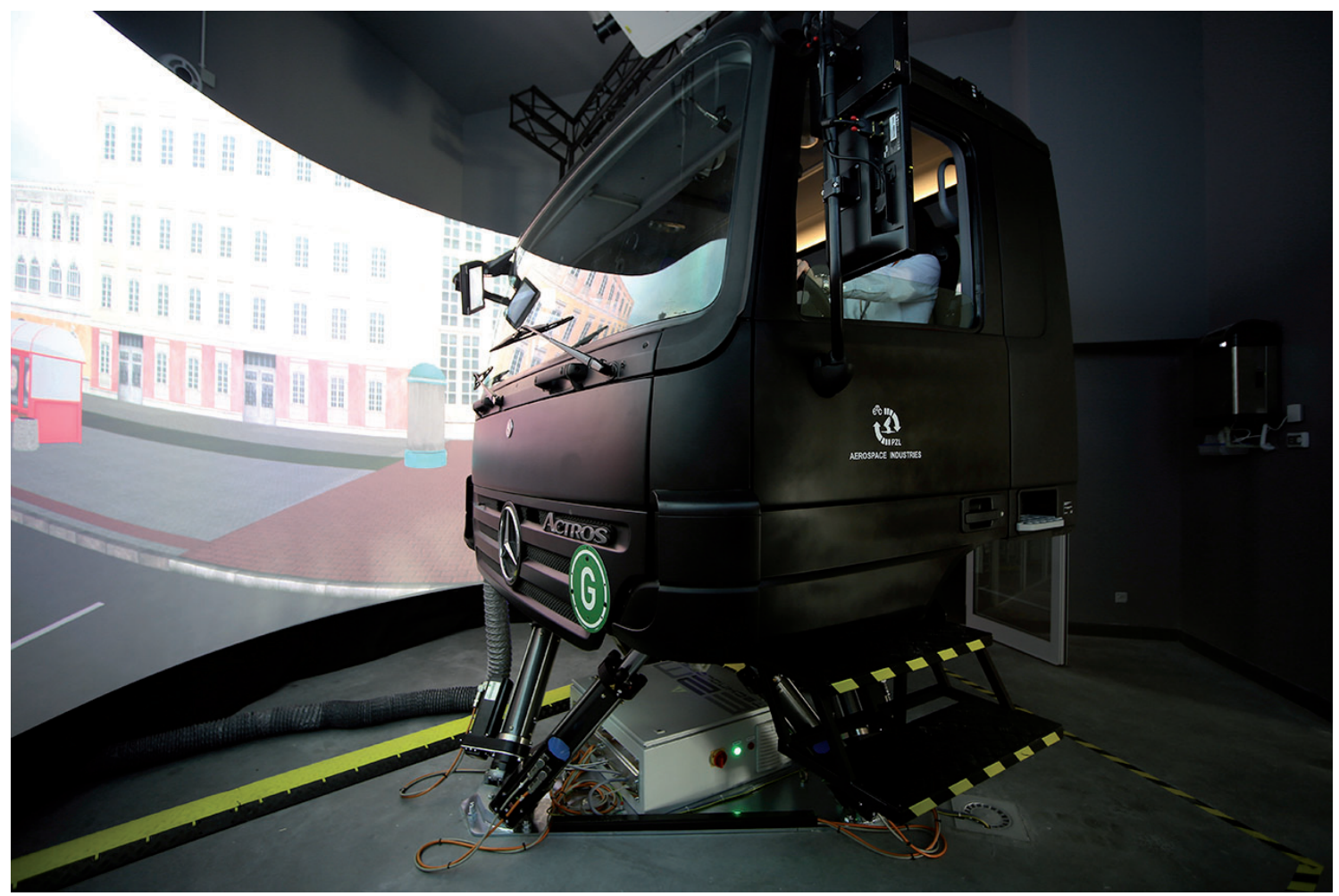

Fig. 1. Simulator truck cabin. 


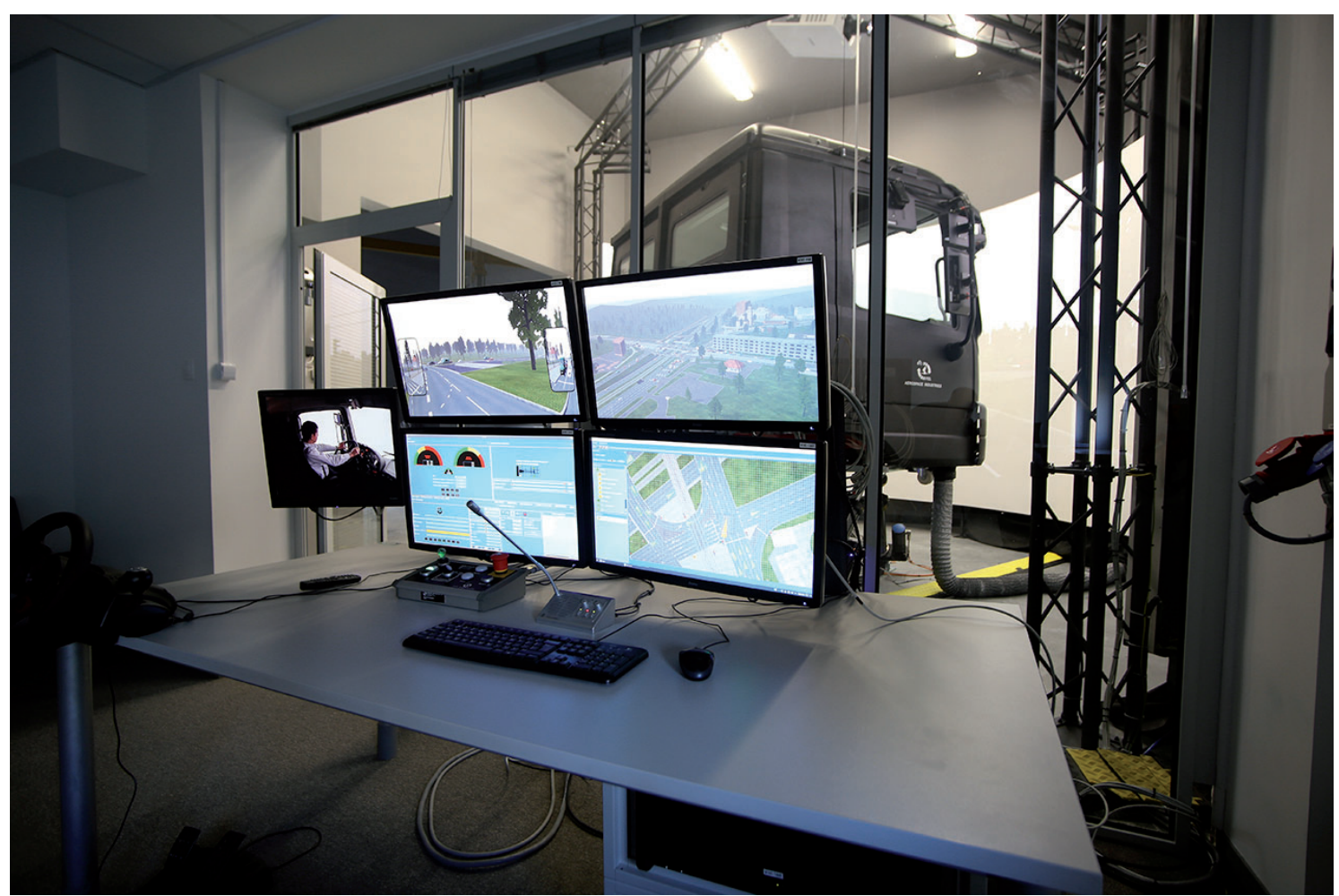

Fig. 2. Instructor (operator) room.

regulation on the device to simulate driving in special conditions (Journal of Laws of 2019, item 2018). The manufacturer of this device is ETC-PZL Aerospace Industries Sp. z o.o.

The main components of the simulator are as follows:

- Mercedes Benz Actros truck cabin with its standard equipment performing the same functions as a normal truck,

- cabin motion system with six degrees of freedom (6 DoF),

- presentation layout on a cylindrical screen with a horizontal field of view of $180^{\circ}$,

- three laser projectors with widescreen ultra extended graphics array (WUXGA) resolution,

- automatic geometric calibration system,

- acoustic background simulation system, generating sound effects heard by the driver and reproducing the sounds heard in the cabin of a real vehicle (e.g. engine noise, sounds of other vehicles in road traffic, alarm signals of specific failures or malfunctions of the truck),

- instructor (operator) room designed to control and operate the truck simulator,

- biomedical and environmental parameters monitoring system.

The simulator truck cabin is presented in fig. 1. Instructor room is presented in fig. 2.

\section{SOFTWARE}

The truck driving simulator is based mainly on software developed by ETC-PZL Aerospace Industries which works with various operating systems, including MS Windows and Unix. It enables the simulation of at least 500 vehicles in joint traffic

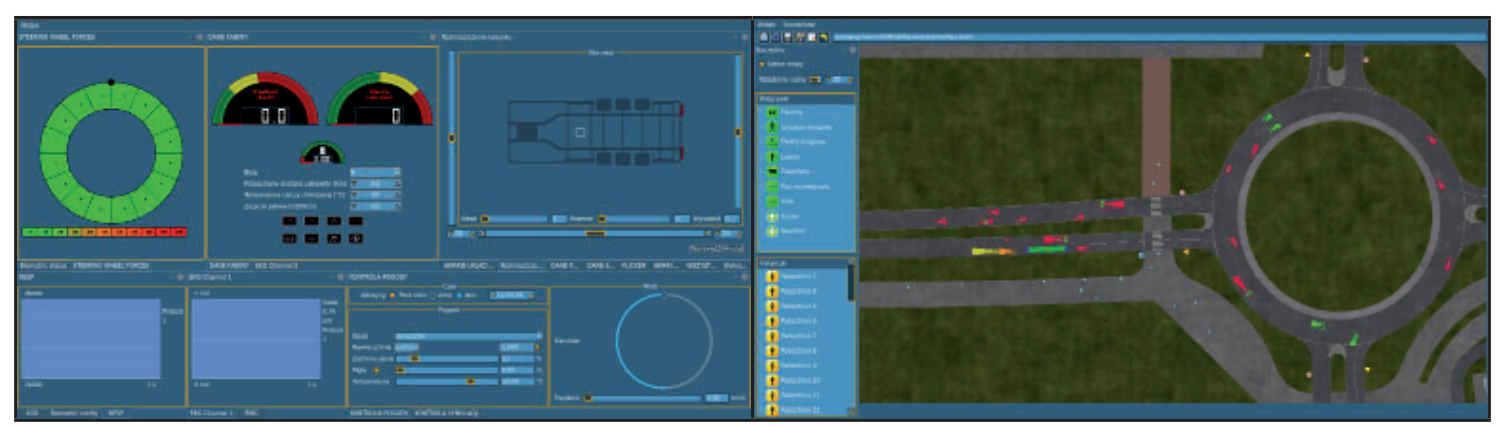

Fig. 3. View of the simulator software main windows. 


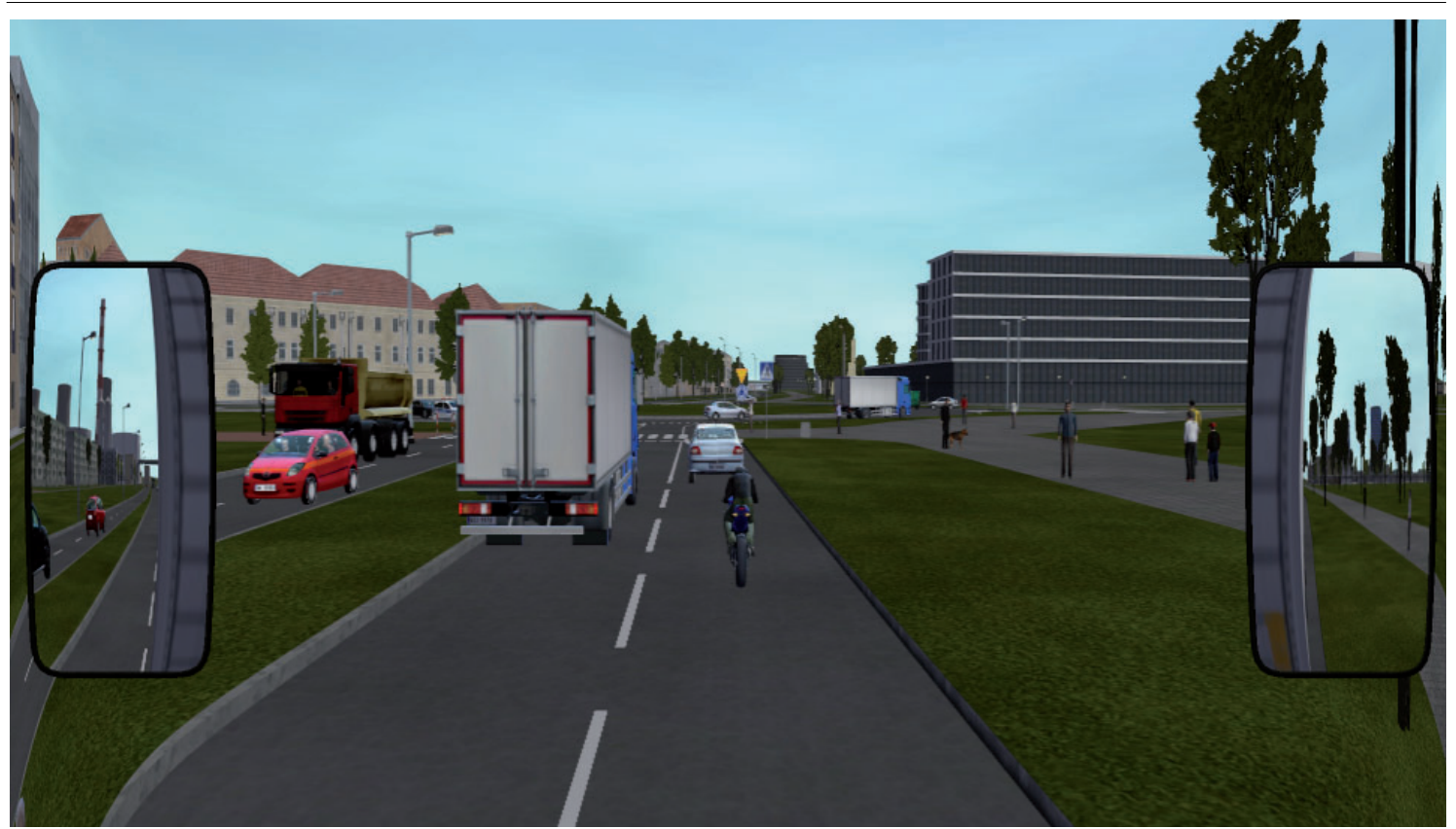

Fig. 4. Sample view of the virtual environment seen from the instructor room.

motion with the vehicle of the trained driver. The software can be installed on a range of commercial off-the-shelf (COTS) hardware platforms and allows for using standard inter-process communication methods [http://www.ai.com.pl]. The software complies with the High Level Architecture (HLA) standard for distributed simulation, used when building a simulation by combining several simulators. The simulator software main windows are presented in fig. 3 .

The high-quality simulator software enables for generating various road conditions, including the following:

- simulation of different times of the day (day and night), seasons (summer and winter) and weather conditions (e.g. rain, snow, fog, gusts of wind),

- simulation of different types of terrain, e.g. city, highway, mountainous terrain,

- simulation of different road effects, e.g. irregularities, holes, puddles, strip icing, oil stains,

- simulation of vehicles in joint traffic with the vehicle of the trainee/examined driver, including passenger vehicles, trucks and privileged vehicles,

- simulation of pedestrians as well as emergency situations involving them, e.g. pedestrian intrusion into the roadway or a drunk person walking near the road,

- simulation of crowds of people, e.g. manifesting on the road,

- simulation of different animals, e.g. dogs, wild boars, going through or entering the roadway,
- simulation of collisions with other road users as well as static objects, e.g. buildings, trees, stops, lanterns,

- simulation of different road situations, including emergencies, e.g. tanker accident, load falling from a vehicle, police check, bough lying on the roadway or falling from a nearby tree, fire or flooding of an area, police officer directing traffic at an intersection,

- simulation of exercises on the manoeuvring area, including a rectangular sliding plate with an optional jerk, 120 or 360 degree sliding bow, slalom, bow riding,

- simulation of a failure of the steered vehicle, e.g. wheel lock, engine seizure, gear lock, exterior light failure, windscreen breakage, explosion, fire, leakage, mirror failure,

- generation of sounds mimicking those heard in a real vehicle, e.g. engine and propulsion system noises, acoustic effects of driving on rough roads, sounds of other vehicles in motion, alarm signals,

- common simulation in a uniform virtual simulation environment using several simulators,

- creating any driving scenarios.

Sample view of the virtual environment seen from the instructor room is presented in fig. 4 .

\section{BIOMEDICAL AND ENVIRONMENTAL PARAMETERS MONITORING SYSTEM}

The truck driving simulator is equipped with a biomedical and environmental parameters monitoring system. The system consists of a small- 


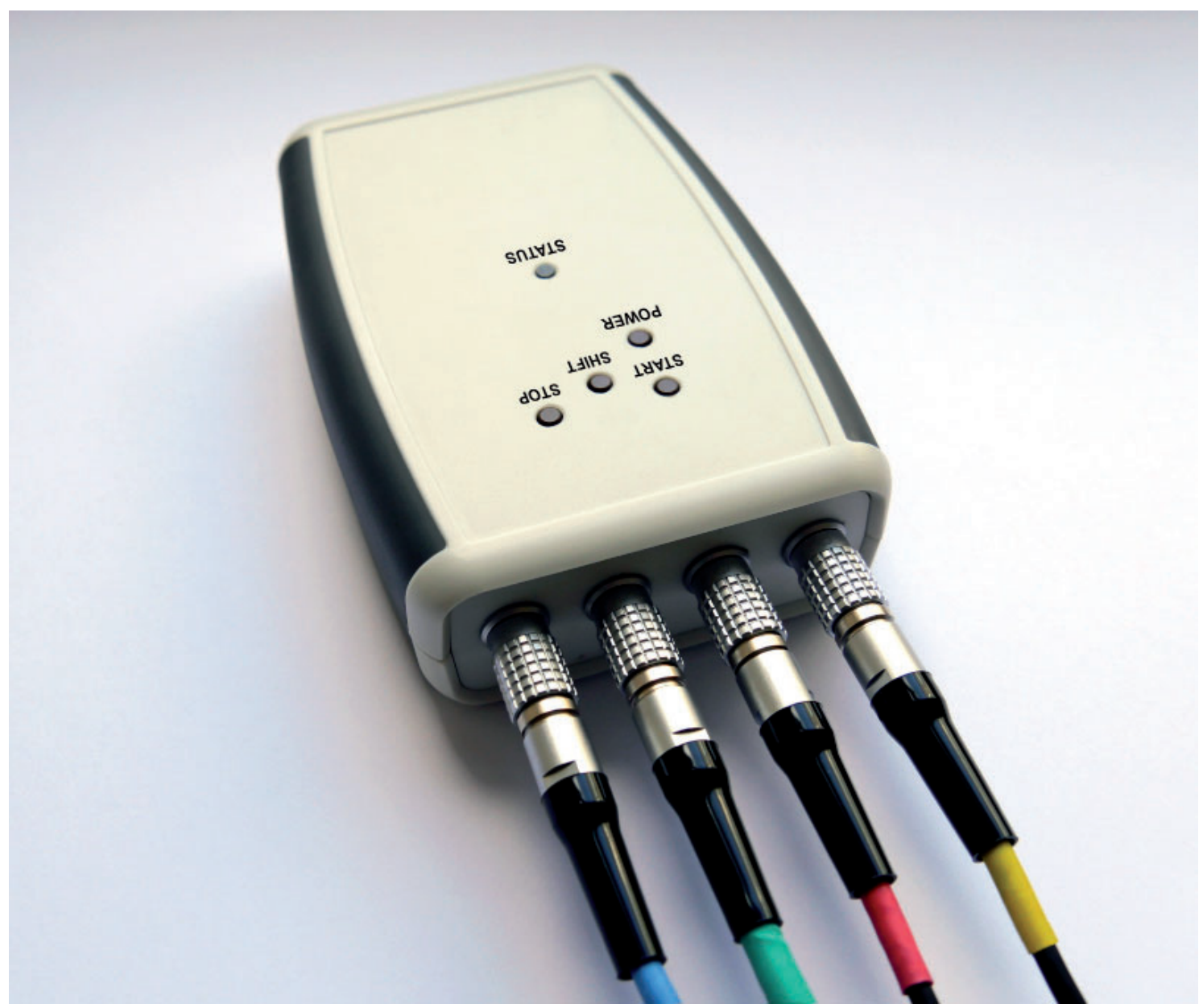

Fig. 5. Biomedical and environmental parameters monitoring system.

sized personal measurement module that can be attached, for example, to the trainee's belt. On the housing of the recorder there are LED indicators of the device status, e.g. standby or recording process, and connections for signals from electrodes and a sensor. A photograph of the measurement system is shown in fig. 5 .

Measurement of the electrical activity of the heart and muscles as well as galvanic skin response (GSR) that can be carried out using this system is based on standard adhesive electrodes attached to the skin of the examined person. Moreover, the respiration signal can be measured by means of a breath sensor attached close to the nose. The system also enables for measuring the steering wheel squeeze based on strain gauges located around its circumference, as well as the critical frequency of flicker/confluence of the light stimulus by the optical indicator located in the truck cabin. Additionally, the system enables for recording accelerations in three axes of the body while driving the truck.

All recorded biomedical and environmental parameters can be presented online and offline on one of the monitor screens in the operator room. It is worth noting that thanks to the recording of biomedical parameters while driving in the simulator, it is possible to assess the current physical condition of the driver, as well as the amount of tension, stress and psychophysiological load experienced by them and related to the task performed in simulated conditions.

\section{CONCLUSION}

The Military Institute of Aviation Medicine's truck simulator is a technologically advanced device intended for conducting research and trainings of drivers in simulated traffic conditions. Thanks to high-quality computer graphics, image displayed on a cylindrical screen and rich acoustics, the simulator creates a very realistic driving environment. Furthermore, thanks to the use of a 6 DoF platform, the trainee can have the kinaesthetic sensations that actually accompany e.g. turning or braking a car, as well as feel the dynamics of the vehicle on various types of surfaces and in various weather conditions. The series of tests 
carried out so far in the simulator has confirmed its usefulness in testing of drivers.

In conclusion, there are many possibilities of using the truck simulator both in training and research, among which the following can be mentioned:

- training of driving skills in various terrain, weather and environmental conditions, including special and difficult ones,

- training of drivers' behaviours in emergency and dangerous situations on the road,
- practicing operator skills on the manoeuvring area,

- assessing psychophysiological load while driving a car,

- investigating psychophysiological reactions of drivers in response to numerous events on the road, especially those that may threaten road safety,

- conducting research on the impact of various subjective and environmental factors and conditions on driving safety.

\section{AUTHORS' DECLARATION:}

Study Design: Paulina Baran, Mariusz Krej, Marcin Piotrowski, Łukasz Dziuda. Data Collection: Paulina Baran, Mariusz Krej, Marcin Piotrowski, Łukasz Dziuda. Manuscript Preparation: Paulina Baran, Mariusz Krej, Marcin Piotrowski, Łukasz Dziuda. The Authors declare that there is no conflict of interest.

\section{REFERENCES}

1. Anderson C, Horne JA. Driving drowsy also worsens driver distraction. Sleep Medicine. 2013; 14(5): 466-468.

2. Andysz A, Waszkowska M, Merecz D, Drabek M. Use of driving simulators in psychological research. Medycyna Pracy. 2010; 61(5): 573-582.

3. Bieliauskas LA. Neuropsychological assessment of geriatric driving competence. Brain Injury. 2005; 19(3): 221-226.

4. Dziuda $Ł$, Biernacki MP, Baran PM, Truszczyński OE. The effects of simulated fog and motion on simulator sickness in a driving simulator and the duration of after-effects. Applied Ergonomics. 2014; 45(3): 406-412.

5. Horne JA, Baulk SD. Awareness of sleepiness when driving. Psychophysiology. 2004; 41: 161-165.

6. Irwin C, ludakhina E, Desbrow B, McCartney D. Effects of acute alcohol consumption on measures of simulated driving: a systematic review and meta-analysis. Accident Analysis \& Prevention. 2017; 102: 248-266.

7. Johns MW, Chapman R, Crowley K, Tucker A. A new method for assessing the risks of drowsiness while driving. Somnologie. 2008; 12: 66-74.

8. Nowosielski RJ, Trick LM, Toxopeus R. Good distractions: testing the effects of listening to an audiobook on driving performance in simple and complex road environments. Accident Analysis \& Prevention. 2018; 111: 202-209.

9. Philip P, Taillard J, Klein E, Sagaspe P, Charles A, Davies WL, Guilleminault C, Bioulac B. Effect of fatigue on performance measured by a driving simulator in automobile drivers. Journal of Psychosomatic Research. 2003; 55(3): 197-200.

10. Pieroni A, Lantieri C, Imine H, Simone A. Light vehicle model for dynamic car simulator. Transport. 2016; 31(2): 242-249.

11. Schmidt E, Decke R, Rasshofer R, Bullinger AC. Psychophysiological responses to short-term cooling during a simulated monotonous driving task. Applied Ergonomics. 2017; 62: 9-18.

12. Scoltock J. Why simulation is on the up. Professional Engineering. 2020; 33(1): 41-43.

13. Törnros JEB, Bolling AK. Mobile phone use - effects of handheld and handsfree phones on driving performance. Accident Analysis \& Prevention. 2005; 37(5): 902-909.

14. Veldstra JL, Bosker WM, De Waard D, Ramaekers JG, Brookhuis KA. Comparing treatment effects of oral THC on simulated and on-the-road driving performance: testing the validity of driving simulator drug research. Psychopharmacology. 2015; 232: 2911-2919.

15. Yan X, Abdel-Aty M, Radwan E, Wang X, Chilakapati P. Validating a driving simulator using surrogate safety measures. Accident Analysis \& Prevention. 2008; 40(1): 274-288.

16. Young MS, Mahfoud JM, Walker GH, Jenkins DP, Stanton NA. Crash dieting: the effects of eating and drinking on driving performance. Accident Analysis \& Prevention. 2008; 40(1): 142-148.

Cite this article as: Baran P, Krej M, Piotrowski M, Dziuda $Ł$. Technical Properties And Research Capabilities Of The Truck Simulator Owned By The Military Institute Of Aviation Medicine - A New Perspective In Research On Truck Drivers. Pol J Aviat Med Bioeng Psychol 2019; 25(3): 26-31. DOI: 10.13174/pjambp.19.05.2021.04 